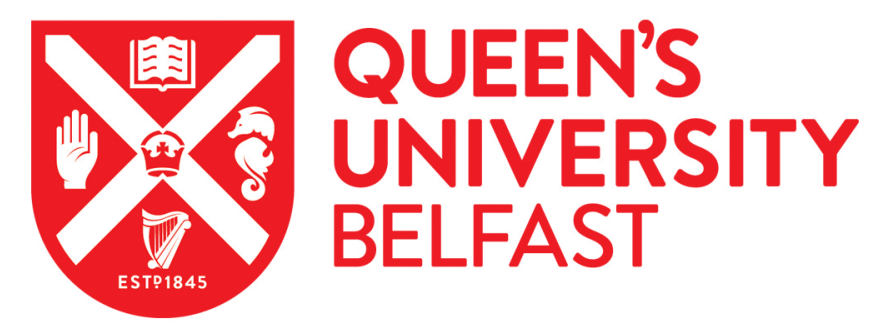

\title{
Learning how to learn using simulation: Unpacking disguised feedback using a qualitative analysis of doctors' telephone talk
}

Eppich, W., Rethans, J-J., Dornan, T., \& Teunissen, P. W. (2018). Learning how to learn using simulation: Unpacking disguised feedback using a qualitative analysis of doctors' telephone talk. Medical teacher, 40(7), 661-667. https://doi.org/10.1080/0142159X.2018.1465183

Published in:

Medical teacher

Document Version:

Peer reviewed version

Queen's University Belfast - Research Portal:

Link to publication record in Queen's University Belfast Research Portal

Publisher rights

Copyright 2018 Taylor \& Francis. This work is made available online in accordance with the publisher's policies. Please refer to any applicable terms of use of the publisher.

\section{General rights}

Copyright for the publications made accessible via the Queen's University Belfast Research Portal is retained by the author(s) and / or other copyright owners and it is a condition of accessing these publications that users recognise and abide by the legal requirements associated with these rights.

Take down policy

The Research Portal is Queen's institutional repository that provides access to Queen's research output. Every effort has been made to ensure that content in the Research Portal does not infringe any person's rights, or applicable UK laws. If you discover content in the Research Portal that you believe breaches copyright or violates any law, please contact openaccess@qub.ac.uk. 
'Learning how to learn' using simulation: Unpacking disguised feedback using a qualitative analysis of doctors' telephone talk

\author{
Walter J. Eppich, MD, MEd \\ Jan-Joost Rethans, MD, PhD \\ Tim Dornan, MD, PhD \\ Pim W. Teunissen, MD, PhD
}

Dr. Eppich is associate professor of paediatrics-emergency medicine and medical education, Northwestern University Feinberg School of Medicine, Chicago, USA

Dr. Rethans is professor of human simulation and director of medical education programs Maastricht University, the Netherlands

Dr. Dornan is professor of medical education, Queens University, Belfast, UK, and emeritus professor at Maastricht University, the Netherlands

Dr. Teunissen is professor of medical education at Maastricht University, the Netherlands 


\section{Corresponding author:}

Walter Eppich, MD, MEd

Ann \& Robert H. Lurie Children's Hospital of Chicago

Division of Emergency Medicine

225 E. Chicago Ave Box 62

Chicago, IL 60611

Telephone: 312-227-6080

Fax: 312-227-9475

Email:w-eppich@northwestern.edu

Each author made substantial contributions to conception and study design. WJE collected all data. Each author contributed to analysis and interpretation of data as well as drafting and reviewing the article critically for important intellectual content. Each author takes take public responsibility for the entire work.

\section{Disclosure statement:}

Dr. Eppich received salary support from the Center for Medical Simulation (Boston/USA) to teach on simulation educator courses. He also receives per diem honoraria from PAEDSIM e.V. to teach on simulation educator courses. There are no other disclosures to report. 
A needs analysis of doctors' telephone talk

\section{Abstract:}

Telephone talk between clinicians represents a substantial workplace activity in postgraduate clinical education, yet junior doctors receive little if any formal training in goal-directed, professional telephone communication. In order to develop a simulation-based educational intervention, we conducted a needs assessment based on thematic analysis of 17 semistructured interviews with doctors-in-training from various training levels and specialties. We identified several essential elements to incorporate into simulation-based telephone talk training, including common challenging situations for junior doctors as well as explicit and informal aspects that promote learning. These elements have implications for both junior doctors and clinical supervisors, including: (a) explicit teaching and feedback and (b) informal conversational interruptions and questions. The latter serve as 'disguised' feedback, which aligns with recent conceptualizations of feedback as 'performance relevant information'. In addition to preparing clinical supervisors to support learning through telephone talk, we propose several potential educational strategies: (a) embedding and integrating telephone communication skills throughout simulation activities and (b) developing stand-alone curricular elements to sensitise junior doctors to 'disguised' feedback during telephone talk as a mechanism to augment future workplace learning, i.e. 'learning how to learn' through simulation. 
A needs analysis of doctors' telephone talk

\section{Practice Points}

1. Doctors-in-training received little if any preparation in how to engage other clinicians over the telephone.

2. Common challenging situations included: calling subspecialists for advice (i.e. calling a consult) or calling more senior colleagues on their team for guidance.

3. Key elements of telephone have implications for both junior doctors and clinical supervisors, including: (a) explicit teaching and feedback and (b) informal conversational interruptions and questions, serve as 'disguised' feedback or performance relevant information.

4. Given its importance, simulation educators should integrate telephone communication skills throughout simulation activities.

5. We should design educational interventions to sensitise junior doctors to 'disguised' feedback during telephone talk as a mechanism to augment future workplace learning, i.e. 'learning how to learn' through simulation. 
A needs analysis of doctors' telephone talk

\section{INTRODUCTION}

Although telephone conversations between doctors and other health professionals represent a significant workplace activity, residents receive little if any training to engage in this professional conversational space. This lack of preparation can negatively affect patient care and potentially lead to patient harm due to incomplete information exchange (Brannen et al. 2009; Kessler et al. 2014; Phitayakorn et al. 2008) and paradoxically may even impair residents' clinical education. Most research in this area frames telephone conversations such those related to 'calling a consult', i.e. calling specialists for advice or consultation, as ones primarily about information exchange (Kessler, Kutka, et al. 2012; Chan, Orlich, et al. 2013; Kessler et al. 2013). This lens leads to training paradigms that necessarily highlight information exchange (Kessler et al. 2015; Kessler, Kalapurayil, et al. 2012) and mnemonics that emphasize primarily monologic rather than dialogic communication protocols, e.g. SBAR (Situation, Background, Assessment, Recommendation) (Haig et al. 2006; Pryor et al. 2014). While such approaches can have significant clinical impact in the setting of patient handoff (Starmer et al. 2014), standardization has limits (Hilligoss \& Moffatt-Bruce 2014). Recent work underscored the importance of familiarity and trust (Chan, Sabir, et al. 2013), the potential for unproductive tensions (Wadhwa \& Lingard 2006) and conflict (Chan et al. 2014).

Building on the assumption that talk mediates learning (Vygotsky 1986; Lave \& Wenger 1991; Wenger 1998), Eppich et al. 2016 outlined how healthcare talk contributes to both patient care and learning from patient care since talk forms the basis of inter-professional collaboration (Eppich et al. 2016). Much of talk's intrinsic learning potential is 'informal' (Eraut 2004; Swanwick 2005) and unplanned as opposed to formal curricular elements. As part of a 
A needs analysis of doctors' telephone talk

larger research program, Eppich and colleagues interviewed medical trainees and used constructivist grounded methodology (Watling \& Lingard 2012; Charmaz 2014) to explore both (a) the role of telephone talk in physicians' clinical education and (b) what promotes learning during telephone talk. Eppich et al. (under review) interviewed 17 doctors-in-training who reported that telephone talk between clinicians, such as themselves and their clinical supervisors, featured prominently in their clinical work. Further, Eppich et al. used a sociocultural analytic lens and found that during telephone talk, doctors-in-training reported not only learned 'how to talk', but also learned 'through talk' partly driven by productive conversational tensions that they experienced. The authors also stressed the need for specific preparation in telephone talk in postgraduate medical education. This current study addresses this gap by further delineating these educational needs.

Simulating telephone talk is feasible, relatively easy to organize and requires no extensive equipment. Prior work has shown that simulation-based role play enhances telephone communication skills (Evens \& Curtis 1983). However, the limited literature on telephone medicine based educational interventions for telephone talk curriculum between providers primarily on monologic communication protocols (Kessler et al. 2015; Podolsky et al. 2015). Therefore, we conducted a targeted needs assessment (Anderson et al. 2008; Thomas et al. 2016) with several aims: (a) to clarify trainee doctors' perceived learning needs; (b) to use their experiences in workplace telephone talk to characterize both explicit and informal elements to incorporate into realistic scenario design and implementation; and (c) to identify salient aspects to integrate into post-simulation debriefings. 
A needs analysis of doctors' telephone talk

\section{METHODS}

We performed a secondary analysis of our existing dataset reported from our larger research program (Eppich et al. under review). Starting with portions of our initial analysis, we re-analysed all interviews using principles of thematic analysis (Braun \& Clarke 2006).

Specifically, we sought evidence relevant for an educational needs assessment to inform scenario design, implementation, and debriefing for both junior doctors and clinical supervisors.

\section{Study setting and participant sampling}

The study took place at an academic medical centre in the Midwestern United States. We invited an initial group of physicians-in-training to participate through targeted recruitment emails based on suggestions from training program directors. Residents and subspecialty fellows were selected for interviews to ensure a spectrum of training levels and specialties. In addition, several residents were invited via email at the recommendations of participants who had already completed their interviews. One participant recruited in this manner was from another large tertiary academic centre in the eastern United States. Participants, who provided informed consent before their interview, received no incentive or compensation. The ethics committee at the primary author's institution approved this study (IRB 2016-120).

In the spirit of reflexivity, we provide the authors' relevant background: (a) all authors are physicians who have significant medical education research experience; (b) WJE and PWT are active clinicians; (c) PWT and TD have extensive research experience using qualitative 
A needs analysis of doctors' telephone talk

methodologies; and (d) WJE and JJR have substantial experience in simulation curriculum development.

\section{Data collection and analysis}

One investigator (WJE) performed all individual semi-structured interviews with a purposive sample of residents and subspecialty fellows across training levels and specialties between December 2015 and February 2017. All interviews explored doctors' patient carerelated telephone conversations with other clinicians such as other doctors, nurses, and health professionals. Open-ended items invited participants to describe their experiences related to telephone talk, including: (a) a recent telephone conversation that stood out and why; (c) challenging situations on the telephone; and (c) their advice to more junior physicians. Additional emergent themes were explored depending on participant responses, including what helped them attain their current abilities.

All interviews were audio-recorded, professionally transcribed, reviewed for accuracy, and de-identified. WJE performed a line-by-line coding of the initial three interviews using constant comparative analysis to create focused codes. TD and PWT reviewed initial focused codes independently to ensure agreement about coding and adequacy of the interview guide. Subsequent focused codes were developed jointly in the research team through independent review of data and collaborative discussion. We collected and analysed our original data in an iterative fashion using constant comparison. At that time, we ended data collection when we identified no new themes and we had achieved theoretical sufficiency (Varpio et al. 2017). For the current study, we applied principles of thematic analysis (Braun and Clarke 2006) to our 
A needs analysis of doctors' telephone talk

entire existing dataset beginning with focused codes we identified in the initial analysis related to: (a) challenging situations, (b) the developmental trajectory from junior to senior doctor-intraining, and (c) what promotes learning on the telephone. Subsequent analytic meetings served to identify recurrent categories and provisional themes with particular relevance for an educational needs assessment. Data were reviewed jointly followed by collaborative discussion about the appropriateness of categories, which were then refined during asynchronous Email exchanges. In line with the principles of thematic analysis. (Braun and Clarke 2006), we incorporated additional data points into existing themes or organized them into new ones. We managed, interpreted, and coded our data using MAXQDA (Berlin, Germany).

\section{RESULTS}

Seventeen physicians-in-training from postgraduate years 1 through 8 with an age range from 26 to 34 years, (mean 29.6) from three academic hospitals participated. See Table 1 for an overview of relevant participant characteristics. Given this diverse sample, our data reflect the varied experiences of physicians-in-training primarily being supervised (i.e. more junior doctors), those mostly supervising others (i.e. more senior doctors), or a mix of both. We identify representative quotations using anonymous participant codes (e.g. P007). The remainder of the results section addresses three major areas: (a) specific educational needs our participants reported in terms of situations and communication challenges, (b) helpful explicit feedback and teaching practices, and (c) informal aspects of telephone conversations that supported doctors' learning.

\section{Specific educational needs}


A needs analysis of doctors' telephone talk

Despite the frequency of work-related telephone conversations during daily clinical

work, nearly all participants specifically mentioned the lack of training in how to engage other clinicians over the telephone. Doctors gained telephone talk skills without "formal coaching" and they needed to "just stumble through" (P006). They learned as a result of "trial and error" (P007) through "experience at the school of hard knocks" (P005). As a result, junior doctors reported inefficient communication patterns that delayed patient care since decision-making required multiple phone calls instead of just one. More senior conversation partners also stressed multiple frustrating and inefficient patterns repeatedly, including:

- Omitting a "one-liner or a framework" (P009) at the outset to frame the conversation

- Giving "rambling" presentations in which "the severity of [the patient's] condition can get lost" (P001) with the result that "nobody's going to pay attention" (P006)

- Presenting irrelevant information while paradoxically leaving out critical details: "If you don't really know what [is] important, you're going to tell me everything....which maybe I don't care about.... I care about the important things" (P011)

Our needs assessment further delineated areas of high educational need related to context and communication challenges. First, our participants raised specific situations that were particularly problematic early in their training: calling subspecialists for advice (i.e. calling a consult) or calling more senior colleagues on their team for guidance. One participant noted 
A needs analysis of doctors' telephone talk

that as a junior doctor, he "struggled to call people for consults, or struggled to call my attendings" (P014). Second, our participants reported several particular challenges that contributed to this sense of 'struggle' in these settings: (a) succinctly summarizing a complex clinical course; (b) conveying urgency effectively; and (c) dealing with pushback, i.e. when requests or proposed courses of action are initially questioned or even rejected without due consideration.

Despite the lack of formal training in telephone talk, however, our participants described a developmental trajectory that eventually allowed them to gain the necessary telephone communication skills. Based on our participants' accounts, we identified several key elements that promoted learning directly and indirectly through workplace telephone talk. These included: (a) explicit teaching and feedback and (b) informal conversational interruptions and questions. Notably, informal conversational interruptions and questions served as valuable implicit feedback that influenced learning. Both explicit and informal elements have relevance for simulations designed to train both junior doctors and clinical supervisors to support and accelerate learning during telephone talk. We now expand on each of these main themes.

\section{Explicit teaching and feedback practices}

Participants shared helpful insights about explicit teaching and feedback interactions over the telephone that should inform how we prepare clinical supervisors for telephone encounters with juniors. Such teaching practices took various forms. First, participants appreciated when supervisors first provided some brief general background information about a given issue before giving specific advice, but without being "condescending" (P006) or using 
A needs analysis of doctors' telephone talk

teaching as a "way to scold you" P008). Second, participants valued when supervisors not only

discussed what to do but also "explain why" (P002), which helped to "learn the thought

process" by hearing "their clinical judgment" (P008). Third, more senior participants highlighted

their use of questions as an explicit educational tool. Rather than simply telling a more junior

colleague what needed to happen next, they sought to promote critical thinking.

[Residents] finish telling me the story and they just stop and I'm like, "So what do you think is going on? Okay, what would you like to do?" [If]... they have a plan that they want to present to me, then I ask, "Okay, so why do you want to do that? What's the reason for doing that?" (P009)

Multiple participants emphasized the value of explicit problem-focused teaching around an immediate patient care need. This perspective is an important one for clinical supervisors to appreciate. "Telephone conversations with a fellow or an attending...tend to be clinical snapshots that stay with me...more than PowerPoint lectures. Effective communication over the phone can be a great educational tool" (P007).

Both more senior and junior doctors-in-training discussed the role of specific feedback on the telephone. For example, supervisors at times explicitly "tend to let [junior doctors] tell their story, because they're learning...how to present a history....and how to tell me their concerns, so I tend to let them go on for a bit. (P001). One senior resident noted that when giving feedback on presentation skills, he found that trying "to frame things that I need [from] them is a good way to teach and train them to know [what] to include in their 
A needs analysis of doctors' telephone talk

presentation...over the phone [next time]" P007. In addition, more junior doctors also valued feedback on their presentation skills, such as: "You could be more organized and concise whenever you present...you could lead with the diagnosis and exactly what you think is going on with the patient" (P014). Further, in terms of clinical reasoning, one second year resident noted that when "calling someone...superior to me, my plan [of care] that I'm presenting is always a 'proposal' that I am asking for feedback on" (P004).

We also identified the potential to prepare junior doctors how to manage their own learning needs. For example, several participants mentioned situations in which they posed questions to solicit explicit teaching from either subspecialty consultants or supervising physicians since "physicians like teaching for the most part... [and] tend to respond pretty positively to that, especially if you don't have any more work at the end of the question" (P015). Conversations grounded in immediate clinical questions also had the potential to lead to discussions around future hypothetical situations. One mid-level emergency medicine resident noted that when speaking with an orthopaedic resident, he was asking about the management of a patient with a fracture:

'What would I typically do with this patient if I were the community and I didn't have an orthopaedic doctor that could see them?' People are really busy.... If you don't ask for it, most of the time they're not going to educate you. (P008)

\section{Informal learning through "disguised feedback": conversational interruptions and questions}


A needs analysis of doctors' telephone talk

The notion of interruptions with relevance for learning featured prominently in our data: either being interrupted or interrupting someone else. Depending on the vantage point, participants framed interruptions as either unpleasant (juniors) or necessary (seniors). More junior doctors with a story to tell appreciated being given the chance to say their "entire piece before [others] step in and ask their questions or give their opinions" (P002).

Even though interruptions were unpleasant, junior participants highlighted their educational value, especially when they caught themselves rambling without a clearly stated purpose to the conversation: "Sometimes you get cut off, or you get a clarifying question, so you get to the point" (P010). One second year resident noted, "as an intern you would have given this long-winded story" and not "have identified the reason for the consult...they interrupt you like, 'Why are you calling me?'” (P015, 93) Alternatively, more senior physicians who listened to a presentation over phone expressed that "if I have no idea of what's going on with the history, then I'Il interrupt them and start asking questions" (P009).

Thus, for seniors the act of interrupting rambling residents appeared to be primarily a matter of efficiency with secondary educational benefit "if it seems like it would save time for me to interrupt" to "steer [rambling residents] back on track" (P011). Representative questions that help "the junior colleague really focus on what's most important..." included: "What are you really concerned about here?" or "What are you worried about could be a danger to this child's life in the next 24 hours?" (P010)

Importantly, multiple participants emphasized the degree to which they were aware of how spontaneous conversational interruptions and questions served as implicit or 'disguised' feedback. This emerging awareness highlighted the potential in making the educational value 
A needs analysis of doctors' telephone talk

of this 'disguised feedback' explicit in order to: (a) accelerate junior doctors' learning, (b) prepare clinical supervisors to accentuate their benefit.

Even if they're not specifically giving you feedback...you can tell if they have all the information that they want, or if they feel like you've left out some things...You get better at unpacking the disguised feedback on the other end of the phone. (P013)

To further underscore its educational significance, our participants reported that implicit feedback in the form of interruptions and questions served as a potent motivator for changing future behaviour. For example, juniors often became aware they were taking too long or providing too much information: "When you're talking longer than you should...there's also inthe-moment, inadvertent feedback... I'm like, 'Okay, I need to start wrapping this up'"' (P009) which helps residents get "better at gauging how much information people want" (P013). One junior noted that when during presentation over the phone someone asks "Okay, why are you calling me?" or "What's the question?", then I know I didn't say the correct thing in the first two sentences" (P016). As a result, "I would try to shape my [future]conversations...to avoid having them have to cut me off" (P006).

Participants experienced interruptions for questions as unpleasant, something about which clinical supervisors should be aware. For example, when calling a consult, "if [more senior physicians] are asking me more parts of the history or physical, that means that this information was relevant...that means that I have not prepared myself [for the call]" (P006). However, "those questions stuck with me...now I ask them" (P009). Thus, participants not only 
A needs analysis of doctors' telephone talk

found general interruptions to prompt a more succinct presentation helpful, but also specific questions that helped them realize what information has relevance in a particular clinical context:

"So, depending on how it's asked [and] what the question is, sometimes when I hang up - I'm like, this is what they care about, which is good to know about in the future... It helps me frame the patient in a way [the specialist] wants to know about them" (P016).

\section{DISCUSSION}

Our findings contribute to a robust needs assessment of telephone talk in postgraduate medical education and complement existing approaches based on mnemonics or cognitive aids (Haig et al. 2006; Podolsky et al. 2015; Kessler et al. 2015). Our study extends this prior work by delineating explicit and informal educational elements of these telephone conversation. We see multiple implications for the use of simulation-based approaches to augment telephone talk.

First, physicians-in-training reported particularly challenging situations to integrate into simulation scenarios, namely calling for subspecialty consultation or calling more senior supervising physicians for advice. Second, we recommend routinely integrating telephone communication into existing scenarios. For example, when caring for a simulated critically-ill patient, simulation participants must often call the critical care unit or other subspecialists for urgent assistance. We recommend that subsequent debriefings should integrate a discussion about the telephone calls embedded in these immersive manikin-based simulations. Third, our findings provide guidance as to how simulated conversation partners should portray their roles 
A needs analysis of doctors' telephone talk

and embody both explicit and implicit feedback. See Table 1 for an overview about how our findings can inform development of a simulation-based telephone talk curriculum for junior doctors.

In addition to explicit feedback and teaching over the phone (Miloslavsky et al. 2015) that has been previously described, our results show that much of the feedback residents receive during telephone talk is implicit or 'disguised'. Thus, our findings align with recent conceptualizations of feedback as 'performance relevant information' (PRI) (van der Leeuw et al. 2017). According to Leeuw and colleagues, PRI "focuses on how learners interpret their performance in the workplace in terms of what is relevant information for their learning" and "includes all potential sources of information for learning arising from the interpretation of one's performance and interaction in the workplace" (p. 2) (van der Leeuw et al. 2017)

Since much of PRI is implicit or 'disguised', we rationalize that sensitising residents to potential PRI during their telephone interactions would enhance their ability to learn from their workplace telephone talk. Thus, we envision an educational intervention that not only trains junior doctors in telephone communication skills, but also prepares them to: (a) identify and incorporate "disguised" feedback, and (b) respectfully solicit the 'why' behind the conversation partners' clinical decision-making and management choices in order to enhance their own learning. Thus, such an educational intervention would potentially enhance junior doctors' abilities to learn from future workplace telephone encounters.

For a dedicated simulation telephone talk intervention, we propose using simulated patient methodology (Cleland et al. 2009). Specifically, the goal would be to prepare physicians-in-training to recognise, integrate and act on "disguised" feedback or PRI that 
A needs analysis of doctors' telephone talk

emerges during healthcare talk. Similarly, a faculty development or 'residents-as-teachers'

initiative could prepare clinical supervisors to deal with underperforming residents and make normally implicit feedback more explicit. These might include providing strategies to interrupt rambling residents respectfully ("Can I pause you for a second? It would help me to hear your clinical question") or to frame a series of additional questions ("In these situations I need additional information, so I have some more specific questions for you...").

Now we will focus the implication of our needs assessment for physicians-in-training and a curriculum that moves beyond a traditional simulation paradigm. In our view, participants traditionally perform and reflect in simulation with the goal of learning to perform in future clinical practice (i.e. 'simulation-as-learning-to-perform'). Such approaches using deliberate practice have shown benefit for communication skills training as has been described elsewhere (Szmuilowicz et al. 2012; Wayne et al. 2012). However, given that simulation may occur infrequently during busy resident clinical training, we plan an alternate yet complementary strategy. By using PRI as a conceptual framework, we propose a simulation intervention in which trainees perform and reflect with the goal of learning how to learn from clinical practice (i.e. 'simulation-as-learning-how-to learn'). Thus, our proposed simulation curriculum would sensitise young doctors to the learning cues or PRI during workplace telephone talk to enhance their future learning. Of course, a fundamental prerequisite would involve establishing a supportive learning environment (Rudolph et al. 2014) by sharing expectations in advance, i.e. "Your conversation partners will portray their role realistically, including interrupting you to ask questions, much like you may experience in your daily clinical work. We will discuss this phenomenon after the simulation ends". 
A needs analysis of doctors' telephone talk

Since the value of disguised feedback during workplace telephone talk represents one of our key findings, we recommend integrating the notion of PRI into simulation activities, including scenarios and debriefings. Short post-simulation debriefings could highlight these moments of potential PRI so that young doctors learn to recognise them explicitly and see their value for their own learning. This approach would inform reflective questions during the debriefing that could prepare residents to ask themselves: "What did I learn from this conversation, how does it impact my clinical reasoning, what would I do differently next time?"

For this study we recruited participants from primarily one academic medical centre. This may limit transferability of our findings to other areas of practice influenced by differing relational and power dimensions. However, we believe that recruitment of participants from various specialties and from three different teaching hospitals mitigates this point to some extent, as each specialty and hospital engenders its own particular culture. It would be interesting to explore healthcare telephone talk in other geographic regions with their unique cultural differences, which also impact debriefings (Chung et al. 2013).

This paper has focused on a needs assessment for simulation-based educational interventions for telephone talk. We plan to develop and implement a simulation-based telephone talk curriculum and assess its effectiveness. Future work is needed to delineate the extent to which the approach of "simulation-as-learning-how-to-learn' translates to workplace learning and performance. Another potential application of this revised educational paradigm might include deliberate training of team reflexive behaviours (Schmutz \& Eppich 2017; Schmutz et al. in press) in order to enhance future individual and team workplace learning. Simulation-based team training may serve as an ideal venue to prepare teams to engage in 
A needs analysis of doctors' telephone talk

these learning behaviours (Schmutz et al. in press), e.g. collective reflection before, during, and after patient care episodes).

\section{CONCLUSIONS}

Telephone talk between clinicians represents an underappreciated workplace activity in postgraduate clinical education. Our needs assessment identified essential elements to incorporate into a simulation-based curriculum to improve telephone communication skills. Common challenging situations for junior doctors include (a) calling subspecialists or more senior clinical supervisors for advice, and (b) structuring presentations succinctly while conveying urgency and the need for consultation convincingly. Simulation scenarios for junior doctors and their clinical supervisors should integrate both explicit and informal aspects, namely explicit teaching and feedback practices as well as disguised feedback or PRI in the form of conversational interruptions and questions. In addition to training telephone communication skills, we see potential in using telephone talk simulations two key ways: (a) to prepare clinical supervisors to support junior doctors' learning, and (b) to sensitise junior doctors to recognise disguised feedback they encounter as a mechanism to augment later workplace learning, i.e. 'learning how to learn' through simulation. 
A needs analysis of doctors' telephone talk

\section{REFERENCES}

Anderson, J.M., Aylor, M.E. \& Leonard, D.T., 2008. Instructional design dogma: creating planned learning experiences in simulation. J Crit Care. 23:595-602.

Brannen, M.L. et al., 2009. Admission handoff communications: clinician's shared understanding of patient severity of illness and problems. J Pat Saf. 5:237-242.

Braun, V. \& Clarke, V., 2006. Using thematic analysis in psychology. Qual Res Psych. 3:77-101.

Chan, T. et al., 2014. Conflict prevention, conflict mitigation, and manifestations of conflict during emergency department consultations. Acad Emerg Med. 21:308-313.

Chan, T., Orlich, D., et al., 2013. Understanding communication between emergency and consulting physicians: a qualitative study that describes and defines the essential elements of the emergency department consultation-referral process for the junior learner. CJEM. 15:42-51.

Chan, T., Sabir, K., et al., 2013. Understanding the impact of residents' interpersonal relationships during emergency department referrals and consultations. J Grad Medical Educ. 5:576-581.

Charmaz, K., 2014. Constructing grounded theory. 2nd ed., London: SAGE Publications Ltd.

Chung, H.S., Dieckmann, P. \& Issenberg, S.B., 2013. It is time to consider cultural differences in debriefing. Sim Healthc. 8:166-170. 
A needs analysis of doctors' telephone talk

Cleland, J.A., Abe, K. \& Rethans, J.-J., 2009. The use of simulated patients in medical education: AMEE Guide No 42. Med Teach. 31:477-486.

Eppich W., Cheng A. 2015. Promoting Excellence and Reflective Learning in Simulation (PEARLS): development and rationale for a blended approach to health care simulation debriefing. Sim Healthc. 10:106-115.

Eppich W.J., Hunt E.A., Duval-Arnould J.M., Siddall V.J., Cheng A. 2015. Structuring feedback and debriefing to achieve mastery learning goals. Acad Med. 90:1501-1508.

Eppich W., Rethans J.-J., Teunissen P.W., Dornan T. 2016. Learning to work together through talk: Continuing professional development in medicine. In: Billett S; Dymock D; Choy S, editors. Supporting learning across working life: Professional and practice-based learning. Cham: Springer Publishing International. pp. 47-73.

Eppich W., Dornan T., Rethans J.-J., Teunissen P.W. "Learning the lingo": A grounded theory study of telephone talk in clinical education. Acad Med. (under review)

Eraut, M., 2004. Informal learning in the workplace. Stud Cont Educ. 26:247-273.

Evens, S. \& Curtis, P., 1983. Using patient-simulators to teach telephone communication skills to health professionals. J Med Educ. 58:894-8.

Haig, K.M., Sutton, S. \& Whittington, J., 2006. SBAR: a shared mental model for improving communication between clinicians. Jt Comm J on Qual Patient Saf. 32:167-175. 
A needs analysis of doctors' telephone talk

Hilligoss, B. \& Moffatt-Bruce, S.D., 2014. The limits of checklists: handoff and narrative thinking. BMJ Qual Saf. 23:528-533.

Kessler, C. et al., 2014. Interunit handoffs of patients and transfers of information: a survey of current practices. Ann Emerg Med. 64:343-349.

Kessler, C., Kutka, B.M. \& Badillo, C., 2012. Consultation in the emergency department: a qualitative analysis and review. J Emerg Med. 42:704-711.

Kessler, C.S. et al., 2013. I'm clear, you're clear, we're all clear: improving consultation communication skills in undergraduate medical education. Acad Med. 88:753-758.

Kessler, C.S. et al., 2015. The 5Cs of Consultation: Training Medical Students to Communicate Effectively in the Emergency Department. J Emerg Med. 49:713-721.

Kessler, C.S., Kalapurayil, P.S., et al., 2012. Validity evidence for a new checklist evaluating consultations, the 5Cs model. Acad Med. 87:1408-1412.

Lave, J. \& Wenger, E., 1991. Situated learning: Legitimate peripheral participation. New York: Cambridge University Press.

Miloslavsky, E.M. et al., 2015. Teaching during consultation: factors affecting the residentfellow teaching interaction. Med Educ. 49:717-730.

Phitayakorn, R. et al., 2008. Patient-care-related telephone communication between general surgery residents and attending surgeons. J Am Coll Surg. 206:742-750. 
A needs analysis of doctors' telephone talk

Podolsky, A., Stern, D.T. \& Peccoralo, L., 2015. The Courteous Consult: A CONSULT Card and Training to Improve Resident Consults. J Grad Med Educ. 7:113-117.

Pryor, E., Woodward-Kron, R. 2014, International medical graduate doctor to doctor telephone communication: A genre perspective. Engl Spec Purp. 35:41-53.

Rudolph, J.W., Raemer, D.B. \& Simon, R., 2014. Establishing a safe container for learning in simulation: the role of the presimulation briefing. Sim Healthc. 9:339-349.

Schmutz, J.B. \& Eppich, W.J., 2017. Promoting Learning and Patient Care Through Shared Reflection: A Conceptual Framework for Team Reflexivity in Health Care. Acad Med. $92: 1555-1563$.

Schmutz, J.B., Lei Z., Eppich, W.J. \& Manser, T. (in press) Reflection in the heat of the moment: The role of in-action team reflexivity in healthcare emergency teams. J Organ Behav.

Schmutz, J.B., Kolbe, M., Eppich, W.J. (in press) Twelve tips for integrating team reflexivity into your simulation-based team training. Med Teach.

Starmer, A.J. et al., 2014. Changes in medical errors after implementation of a handoff program. NEJM, 371:1803-1812.

Swanwick, T., 2005. Informal learning in postgraduate medical education: from cognitivism to 'culturism'. Med Educ. 39:859-865.

Szmuilowicz, E. et al., 2012. Improving residents' code status discussion skills: a randomized trial. J Palliat Med. 15:768-774. 
A needs analysis of doctors' telephone talk

Thomas, P.A. et al. eds., 2016. Curriculum Development for Medical Education. A Six-Step

Approach, 3rd ed., Baltimore: The Johns Hopkins University Press.

van der Leeuw, R.M., Teunissen, P.W. \& Van Der Vleuten, C.P.M., 2017. Broadening the Scope of Feedback to Promote Its Relevance to Workplace Learning. Acad Med. [Epub ahead of print]

Vygotsky, L.S., 1986. Thought and language (rev. ed.). Cambridge, Massachusetts: The MIT Press.

Wadhwa, A. \& Lingard, L., 2006. A qualitative study examining tensions in interdoctor telephone consultations. Med Educ. 40:759-767.

Watling, C.J. \& Lingard, L., 2012. Grounded theory in medical education research: AMEE Guide No. 70. Med Teach. 34:850-861.

Wayne, D.B. et al., 2012. Code status discussion skill retention in internal medicine residents: one-year follow-up. J Palliat Med. 15:1325-1328.

Wenger, E., 1998. Communities of practice: Learning, meaning, and identity. New York: Cambridge University Press. 
Table 1 Participant characteristics

\begin{tabular}{|c|c|c|c|c|c|c|c|c|}
\hline Participant characteristics & \multicolumn{8}{|c|}{ Proportion of total $(n=17)$ in absolute numbers } \\
\hline Gender & \multicolumn{8}{|c|}{$\begin{array}{l}\text { Male (11) } \\
\text { Female (6) }\end{array}$} \\
\hline Training level & & & $\begin{array}{r}\text { Sub } \\
\text { C }\end{array}$ & $\begin{array}{l}\text { Resider } \\
\text { pecialty } \\
\text { ief resic }\end{array}$ & $\begin{array}{l}\text { ts* (11) } \\
\text { fellows* } \\
\text { ent*** }\end{array}$ & $\begin{array}{l}\text { * (5) } \\
\text { 1) }\end{array}$ & 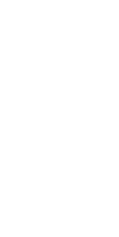 & \\
\hline Training years after graduation & PGY 1 & PGY 2 & PGY 3 & PGY 4 & PGY 5 & PGY 6 & PGY 7 & PGY 8 \\
\hline i.e. post-graduate year (PGY) & 4 & 2 & 5 & 3 & 1 & 1 & 0 & 1 \\
\hline Specialty/Training Program & & Genera & $\begin{array}{r}\text { or subs } \\
\text { Em }\end{array}$ & $\begin{array}{l}\text { pecialty } \\
\text { ergency } \\
\text { Orthopa } \\
\text { Surge } \\
\text { ternal m }\end{array}$ & $\begin{array}{l}\text { oediatr } \\
\text { nedicine } \\
\text { edics (1) } \\
\text { ry (1) } \\
\text { edicine }\end{array}$ & $\begin{array}{l}\text { c progra } \\
\text { (4) } \\
\text { 1) }\end{array}$ & ns (10) & \\
\hline
\end{tabular}

* Resident $=$ junior or senior house office in a general training program

**Subspecialty fellow $=$ Registrar in a subspecialty training program

$* * *$ Chief resident $=$ training program graduate who helps administer training program, 
TABLE 2

Key elements of a workplace-informed simulation-based telephone talk curriculum for junior doctors, including two complementary approaches

\begin{tabular}{|c|c|c|}
\hline & \multicolumn{2}{|c|}{ Type of simulation** } \\
\hline $\begin{array}{c}\text { Curriculum Design } \\
\text { Element* }\end{array}$ & 'Learning-to-perform' & 'Learning-how-to-learn' \\
\hline $\begin{array}{l}\text { Learning goals and } \\
\text { objectives }\end{array}$ & $\begin{array}{l}\text { - Call a consult by delivering a concise, focused presentations } \\
\text { on the telephone tailored to the conversation partner } \\
\text { - Demonstrate strategies to deal with pushback }\end{array}$ & $\begin{array}{l}\text { - Identify performance relevant information (interruptions, } \\
\text { - } \text { - Solicit the 'why' behind decision-making or the supervisor's } \\
\text { train of thought when clinical reasoning not clear } \\
\text { - Apply a framework to promote self-reflection about } \\
\text { telephone conversations that did not go well }\end{array}$ \\
\hline $\begin{array}{l}\text { Establishing a } \\
\text { supportive learning } \\
\text { environment) }\end{array}$ & \multicolumn{2}{|c|}{$\begin{array}{l}\text { - Outline purpose of the session, learning goals, establish ground rules (Rudolph et al. 2014) } \\
\text { - Solicit from learners what they are working on with their telephone communication skills } \\
\text { - } \quad \text { Frame scenarios as realistic, including potential for simulated conversation partners to interrupt with questions } \\
\text { - } \text { phone call; to discuss implicit for 'disguised' feedback) }\end{array}$} \\
\hline $\begin{array}{l}\text { Overview of an } \\
\text { example simulation } \\
\text { scenario }\end{array}$ & \multicolumn{2}{|c|}{$\begin{array}{l}\text { Instructions to participant: } \\
\text { "You've taken overnight sign-out on a patient (ED or ward) and you need to call the endocrine specialist for a medically complex } \\
\text { patient who has become acutely unwell and has critical new electrolyte abnormalities. Your supervising doctor is concerned about an } \\
\text { endocrine issue. Please review the medical record to complement the information you received in sign-out and call the endocrine } \\
\text { specialist to come and assess the patient. Of note, you have not had time to examine the patient." } \\
\text { During the phone call, the simulated endocrine specialist expresses that formal consultation is unnecessary at that moment or } \\
\text { inappropriate altogether. }\end{array}$} \\
\hline & $\begin{array}{l}\text { Focus the scenario on a concise presentation, consider teaching } \\
\text { an established framework, e.g. } \\
-5 C^{\prime} \text { S of calling a consult (Kessler et al. 2015): Contact, } \\
\text { Communicate, Core Question, Collaborate, Close the Loop } \\
\text {-SBAR (Situation, Background, Assessment, } \\
\text { Recommendation)(Haig et al. 2006) }\end{array}$ & $\begin{array}{l}\text { Train simulated conversation partner to respond in ways that } \\
\text { represent 'disguised' feedback', e.g. (a) Interrupt respectfully if } \\
\text { trainee rambles or does not provide a framing statement or clear } \\
\text { clinical question, and (b) pose information-seeking questions if } \\
\text { key information is left out. } \\
\text { Focus the debriefing on strategies that promote learners to } \\
\text { assess their own performance and include reflective questions } \\
\text { about potential PRI in order to make the implicit explicit. }\end{array}$ \\
\hline
\end{tabular}




\begin{tabular}{|c|c|c|}
\hline \multirow{2}{*}{$\begin{array}{l}\text { Scenario } \\
\text { implementation } \\
\text { and debriefing }\end{array}$} & $\begin{array}{l}\text { Consider pause and discuss and providing focused feedback } \\
\text { according to guidelines of deliberate practice and mastery } \\
\text { learning (Eppich et al. 2015) }\end{array}$ & \\
\hline & $\begin{array}{l}\text { "What worked well/did not } \\
\text { 'Learning-to-perform' } \\
\text { Provide specific feedback about what worked well and what } \\
\text { needs improvement } \\
\text { "What are you taking away for }\end{array}$ & $\begin{array}{l}\text { Well from your perspective?" } \\
\text { 'Learning-how-to-learn' } \\
\text { "What kind of cues from [your conversation partner] helped you } \\
\text { know how you were doing?" } \\
\text { about your presentation?" } \\
\text { rnext telephone conversation?" }\end{array}$ \\
\hline $\begin{array}{l}\text { Key considerations } \\
\text { for both forms of } \\
\text { simulation }\end{array}$ & \multicolumn{2}{|c|}{ Coach simulated conversation partners to portray their role in line with learning goals and objectives } \\
\hline
\end{tabular}

*Curriculum design elements based on literature review and our findings

** May include both complementary types of simulation 